\title{
Stress-Corrosion Cracking Susceptibility of the Superplastically Formed 5083 Aluminum Alloy in 3.5 Pct $\mathrm{NaCl}$ Solution
}

\author{
J.C. CHANG and T.H. CHUANG
}

\begin{abstract}
The slow strain rate test (SSRT) method was employed to study the stress corrosion cracking (SCC) susceptibility of the superplastic $5083 \mathrm{Al}$ alloy in a $3.5 \mathrm{pct} \mathrm{NaCl}$ solution after superplastic forming and various heat treatments. Experimental results showed that both superplastically formed specimens and specimens subject to the same thermal processes as that used in superplastic forming suffered severe SCC susceptibility, and obvious intergranular fracture surfaces were also observed. Furthermore, scanning transmission electron microscopy (STEM) and energy-dispersive X-ray spectroscopy (EDS) analyses demonstrated that the thermal processes of superplastic forming led to continuously distributed precipitation layers of $\beta$ phase $\left(\mathrm{Mg}_{2} \mathrm{Al}_{3}\right)$ at grain boundaries, i.e., sensitization had occurred. However, postforming annealing treatment at $345{ }^{\circ} \mathrm{C}$ for 1 hour eliminated the sensitization effect of both specimens. In this case, the SCC susceptibility was alleviated, and the fracture surfaces changed to a transgranular dimpled structure, characteristic of that found in the as-received specimen. From the metallographic observations, it was also seen that a number of cavities appeared at the grain boundaries of the superplastically formed specimen. However, the cavitation effect on SCC susceptibility is minor in comparison with the sensitization effect.
\end{abstract}

\section{INTRODUCTION}

THE $5083 \mathrm{Al}$ alloy has been widely used as a structural material in the marine environment. Grain refinement of this alloy can be obtained by thermomechanical treatment, which improves its mechanical properties and results in superplasticity. ${ }^{[1]}$ Using the superplastivity of material, a superplastic forming technology has been developed, which has become important in industries that manufacture more complex workpieces. This process might replace the conventional stamping processes, especially for those materials with lower formability. ${ }^{[2]}$ A superplastic $5083 \mathrm{Al}$ alloy ( $\mathrm{Al}$ 5083SP) has been commercialized and several superplastically formed components have been produced for the automotive industry to reduce vehicle weight and improve fuel efficiency. ${ }^{[3]}$ The alloy also has potential application in architectural structures. However, it has been reported that $\mathrm{Al}-\mathrm{Mg}$ alloys containing more than 3 wt pct $\mathrm{Mg}$, including the $5083 \mathrm{Al}$ alloy, will be sensitized at temperatures above $100{ }^{\circ} \mathrm{C}$, which can be attributed to the formation of continuous precipitation of the highly anodic $\beta$ phase $\left(\mathrm{Mg}_{2} \mathrm{Al}_{3}\right)$ at grain boundaries. ${ }^{[4,5,6]}$

During exposure to corrosive environments, galvanic effect occurs between the grain boundary precipitates and the grain interiors, which leads to severe anodic attack at grain boundaries. This phenomenon causes an increase of stress corrosion cracking (SCC) susceptibility in this alloy. Since the superplastic forming process of an $\mathrm{Al}$ 5083SP alloy is performed at a temperature between $450{ }^{\circ} \mathrm{C}$ and $500{ }^{\circ} \mathrm{C},{ }^{[7]} \mathrm{SCC}$ susceptibility should be noted. Furthermore,

J.C. CHANG, Associate Researcher, formerly with the Institute of Materials Science and Engineering, National Taiwan University, is with the Chemical Systems Research Division, Chung Shan Institute of Science and Technology, Lung-Tan, 325, Taiwan, Republic of China. T.H. CHUANG, Professor, is with the Institute of Materials Science and Engineering, National Taiwan University, Taipei, 106, Taiwan, Republic of China.

Manuscript submitted April 7, 1998. another undesirable phenomenon, i.e., the formation of cavities, could occur during the superplastic forming of certain alloys, especially for aluminum alloys. ${ }^{[7-10]}$ The cavitation not only deteriorates the mechanical properties of this alloy but also increases its susceptibility to corrosion.

Although the superplastic formability of an $\mathrm{Al}$ 5083SP alloy has been evaluated by many researchers ${ }^{[8-12]}$ studies of the corrosion behavior of this alloy are limited. ${ }^{[13,14]}$ In our previous study, ${ }^{[13]}$ it was found that a superplastically formed $\mathrm{Al}$ 5083SP alloy revealed an increased tendency for intergranular corrosion, which may cause the increase of the SCC susceptibility of this alloy. However, to the authors' knowledge, no work concerning SCC for the superplastically formed Al 5083 alloy has been reported, even though it would be very important from a practical point of view. In the present work, therefore, the SCC behavior of this alloy before and after superplastic forming was further investigated using the slow strain rate test (SSRT) method. For comparison, specimens treated with the same thermal process as used in superplastic forming were also studied.

The metallurgical microstructures as well as the morphology of the fractured specimens were observed under a scanning electron microscope (SEM). In addition, a scanning transmission electron microscope (STEM) with energy-dispersive X-ray spectroscopy (EDS) was employed to examine the microstructure of specimens for this Al 5083SP alloy under various thermal and forming processes. Through these experimental results, the effects of sensitization and cavitation on the SCC of the superplastic Al 5083SP alloy are examined and discussed.

\section{EXPERIMENTAL}

A commercial Al 5083SP alloy supplied by SKY Aluminum Co. Ltd. (Tokyo, Japan), designated as S1, with a thickness of $2 \mathrm{~mm}$ was used in this study. A metallographic 


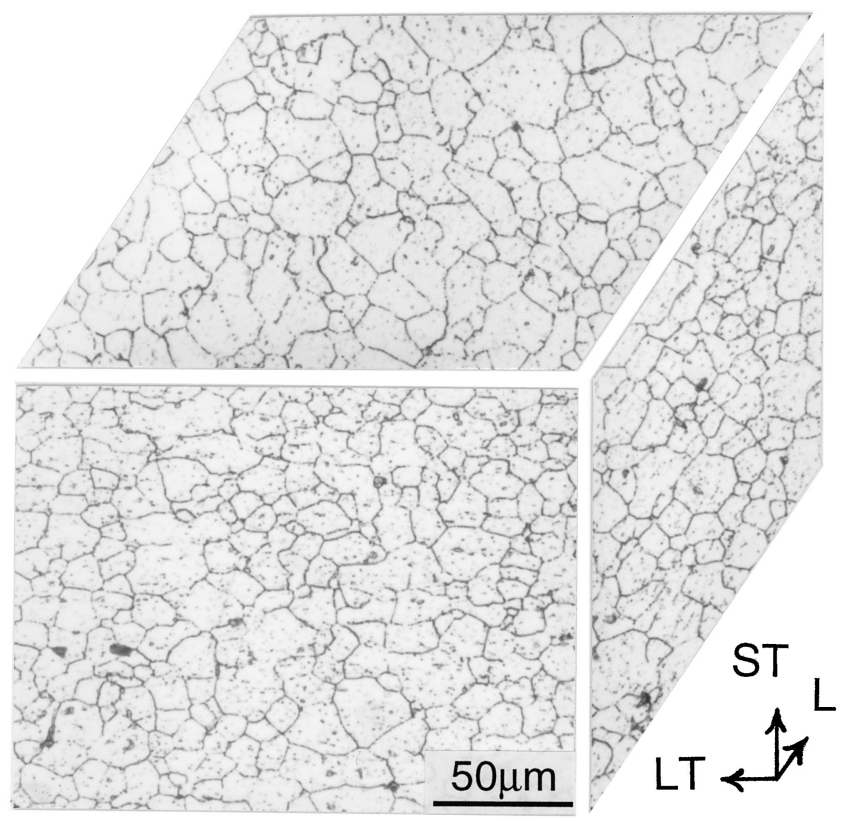

Fig. 1-Typical three-dimensional microstructure of the as-received $\mathrm{Al}$ 5083SP alloy used in this study.

photograph of the as-received alloy revealed a fine-grain microstructure, as shown in Figure 1. The mean intercepts of grain dimensions in ST, LT, and L directions (ST: short transverse, LT: longitudinal transverse, and L: longitudinal) measured according to ASTM E112 were 9.6, 7.5, and 6.6 $\mu \mathrm{m}$, respectively. The chemical composition of this alloy as analyzed by inductively coupled plasma atomic emission spectroscopy (ICP-AES) is given in Table I. A $3.5 \mathrm{pct} \mathrm{NaCl}$ solution was prepared using reagent grade chemical and high-purity deionized water (Millipore Milli-Q SP, 18 $\mathrm{M} \Omega \mathrm{cm}$ ).

Disk specimens with a diameter of $13 \mathrm{~cm}$ were cut from the Al 5083SP sheet alloy and superplastically formed into pan-shaped workpieces (designated S2) in a cylindrical die by argon blowing with a pressure of $0.35 \mathrm{MPa}$ (50 psi) at $500{ }^{\circ} \mathrm{C}$ for 1 hour. The diameter and forming height of the pan-shaped workpieces were 11 and $3 \mathrm{~cm}$, respectively. After superplastic forming, some specimens were further annealed at $345^{\circ} \mathrm{C}$ for 1 hour and designated as $\mathrm{S} 4$. For comparison, specimens of the Al 5083SP alloy were also heat treated under the same thermal processes as those were superplastically formed and designated as S3. Postforming annealing was also conducted for the heat-treated specimens (S3), which were designated as S5. The forming and thermal processes of all these specimens are summarized in Table II.

For SCC tests, rectangular tensile specimens with a gage length of $25 \mathrm{~mm}$ and width of $6 \mathrm{~mm}$ (ASTM E8M-92) were used. The tensile axis was parallel to the longitudinal direction for all the specimens tested in this work. The superplastically formed specimens, S2 and S4, were cut

Table I. Chemical Composition of the Al 5083SP Alloy (Weight Percent)

\begin{tabular}{ccccccccc}
\hline $\mathrm{Mg}$ & $\mathrm{Mn}$ & $\mathrm{Cr}$ & $\mathrm{Si}$ & $\mathrm{Fe}$ & $\mathrm{Cu}$ & $\mathrm{Ti}$ & $\mathrm{Zn}$ & $\mathrm{Al}$ \\
\hline 4.46 & 0.67 & 0.10 & 0.09 & 0.05 & 0.02 & 0.01 & 0.01 & bal \\
\hline
\end{tabular}

Table II. Various Material Processes for Al 5083SP Alloy in the Present Study and the Accompanying Effects on SCC Susceptibility

\begin{tabular}{lll}
\hline Specimen & \multicolumn{1}{c}{ Material Processes } & Detrimental Effects \\
\hline S1 & $\begin{array}{l}\text { as-received } \\
\text { superplastically formed* }\end{array}$ & $\begin{array}{c}\text { - } \\
\text { sensitization and } \\
\text { cativation }\end{array}$ \\
S3 & $\begin{array}{c}\text { heat treated with the same } \\
\text { thermal process as super- }\end{array}$ & $\begin{array}{c}\text { sensitization } \\
\text { plastic forming }\end{array}$ \\
& S2 + postforming anneal- & cavitation \\
S4 & ing treatment** & \\
& S3 + postforming anneal- & - \\
S5 & ing treatment** & \\
&
\end{tabular}

*Superplastically formed under $0.35 \mathrm{MPa}(50 \mathrm{psi})$ at $500{ }^{\circ} \mathrm{C}$ for $1 \mathrm{~h}$ and then furnace cooled.

**Postforming annealed at $345^{\circ} \mathrm{C}$ for $1 \mathrm{~h}$ then air cooled.

through the central section of the pan bottom and then polished to a thickness of $1 \mathrm{~mm}$, while the thickness of specimens S1, S3, and S5 remained $2 \mathrm{~mm}$. The surfaces of all the specimens were polished with emery paper to 600 grit, degreased with acetone in a supersonic cleaning bath and rinsed with deionized water. The tensile properties of the various heat-treated specimens were tested at a strain rate of $10^{-3} / \mathrm{s}$ in air, while the SCC susceptibility was evaluated by the SSRT according to ASTM G129-96 with a strain rate of $4 \times 10^{-6} / \mathrm{s}$. The SSRT was conducted in air and in an aerated 3.5 pct $\mathrm{NaCl}$ solution, respectively. For calculating the elongation of each specimen, the ends of the fractured specimens were fitted carefully and the length between gage marks was measured according to ASTM B557M. The elongation reported in this work was expressed as a percentage of the original gage length.

For optically metallographic observation, the specimens were prepared by polishing and etching with Graf Sergeant reagent $\left(15.5 \mathrm{~mL} \mathrm{HNO}_{3}, 0.5 \mathrm{~mL} \mathrm{HF}, 3 \mathrm{~g} \mathrm{CrCO}_{3}\right.$, and 84 $\mathrm{mL}$ deionized water). ${ }^{[10]}$ To identify the $\beta$ phase precipitates, thin foils of the various specimens were mechanically polished and then electrochemically polished using twin-jet electropolishing equipment in a solution of $33 \mathrm{pct} \mathrm{HNO}_{3}$ in methanol. They were then examined by STEM (JEOL* JEM

*JEOL is a trademark of Japan Electron Optics Ltd., Tokyo.

2000EX) together with EDS. An SEM (PHILIPS** SEM

**PHILIPS is a trademark of Philips Electronic Instruments Corp., Mahwah, NJ.

515) was also employed to observe the fractured surfaces after SSRT tests.

\section{RESULTS}

Figure 2(a) shows a typical pan-shaped workpiece of the Al 5083SP alloy after superplastic forming. The central cross-sectional profile of such a workpiece is shown in Figure 2(b), which reveals that the thickness is not uniform, usually being thinner at the corner. Therefore, the tensile specimens machined from these superplastically formed workpieces were further polished to obtain a uniform thickness of $1 \mathrm{~mm}$. It was also found that the grain size of the 

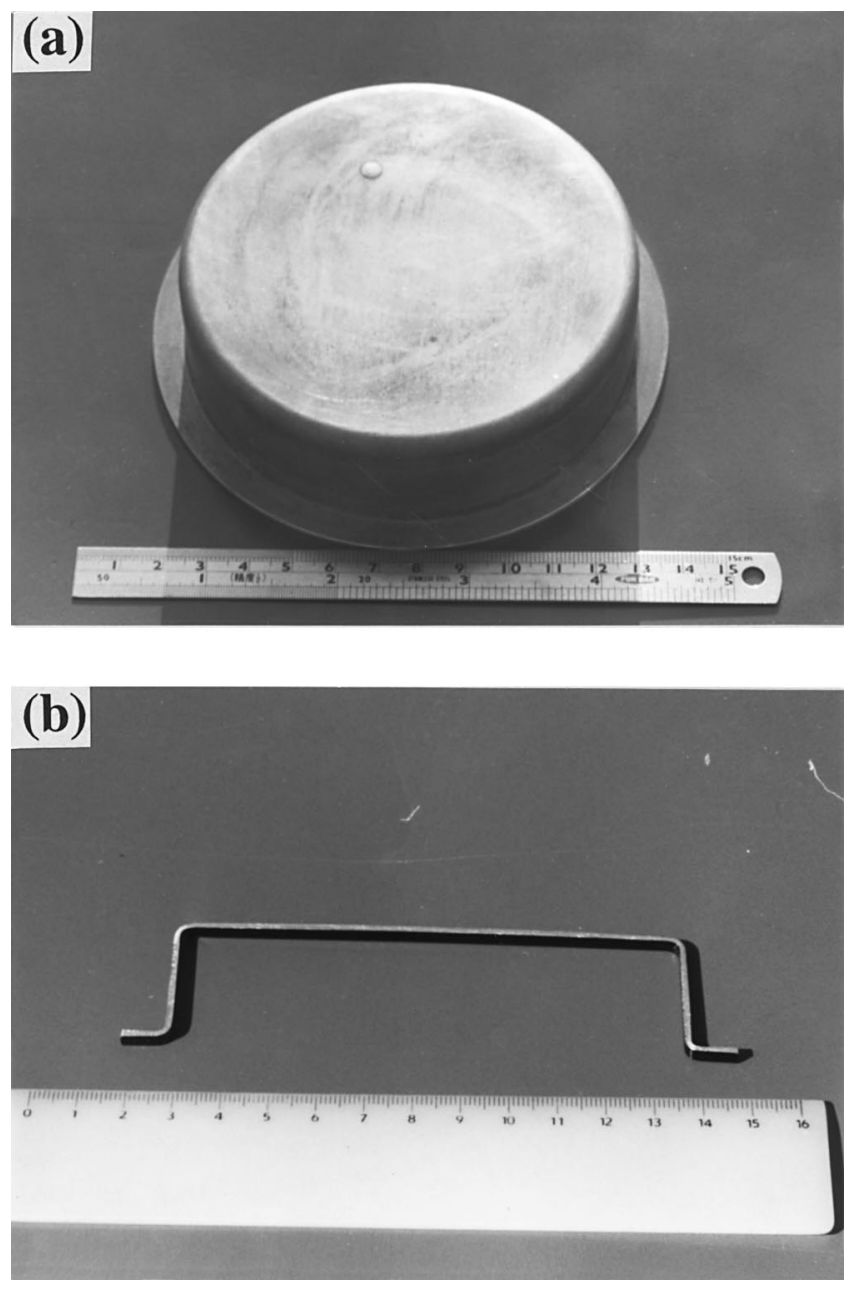

Fig. 2-(a) A typical pan-shaped Al 5083SP workpiece after superplastic forming. (b) The central cross-sectional profile of the workpiece.

superplastically formed specimens (S2) increased by about $65 \mathrm{pct}$ as compared to that of the as-received material. ${ }^{[13]}$ The grain-growth rate was similar to that obtained in a tensile test of this alloy at $550{ }^{\circ} \mathrm{C}$, as reported by Verma et al. ${ }^{[8]} \mathrm{On}$ the other hand, the grain size of the heat-treated specimens without superplastic forming (S3 and S5) did not appreciably change. A number of cavities appear in the superplastically formed specimens, both those without (S2) and those with (S4) postannealed, can be seen in Figure 3. In addition to the large cavities formed in the intersection of triple grain boundaries, many small cavities in the size of micrometer range were also found at the grain boundaries. The cavitation is similar to that of the superplastically formed $\mathrm{Al} 7475$ workpieces in our previous study. ${ }^{[15]}$

Figure 4 shows the microstructure of the various specimens of the $\mathrm{Al}$ 5083SP alloy. For the as-received specimen (S1), grain boundary precipitation was hardly found (Figure 4(a)). However, in the superplastically formed specimen (S2) and the heat-treated specimen (S3), there existed continuously distributed precipitates, indicated by arrows, at grain boundaries, as shown in Figure 4(b) and (c), respectively. The STEM-EDS analyses revealed that the grain boundary precipitation layer in $\mathrm{S} 2$ specimens possessed a composition of $\mathrm{Mg}_{2} \mathrm{Al}_{3}$ ( $\beta$ phase). A similar result was obtained for the S3 specimens. Postforming annealing treatment for S2 and
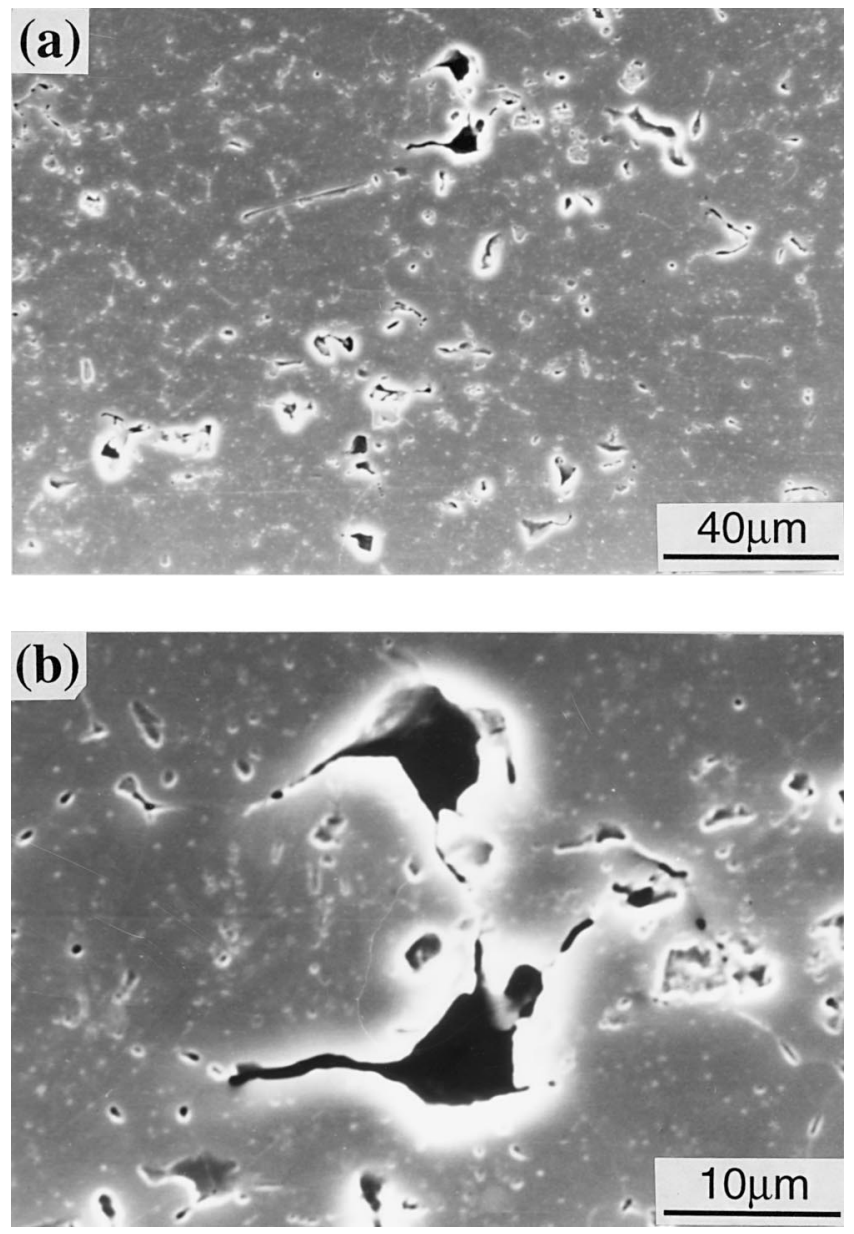

Fig. 3-(a) Appearance of the cavities at the grain boundaries of a superplastically formed Al 5083SP specimen. (b) A magnification of (a) showing the large cavities at the intersections of triple grain boundaries.

S3 specimens caused their intergranular precipitation layers to become discrete particles $\left(\mathrm{Mg}_{2} \mathrm{Al}_{3}\right)$, indicated by arrows, as shown in Figures 4(d) and (e) for S4 and S5 specimens, respectively. Meanwhile, it is worth noting that cavities did not show in Figure 4. The chemical composition of these grain boundary precipitates in S4 and S5 specimens was similar to that found in $\mathrm{S} 2$ and $\mathrm{S} 3$ specimens as identified by STEM-EDS. From Table III, it is revealed that the tensile strength and elongation percentage of the superplastically formed specimen (S2) were approximately 10 and $40 \mathrm{pct}$ lower than those of the as-received specimen (S1), respectively. After postforming annealing treatment, the tensile strength of the specimen (S4) remained almost unchanged, while the elongation was improved by about $10 \mathrm{pct}$, as compared with the superplastically formed specimen (S2).

The stress-strain curves of SSRT in air and in $3.5 \mathrm{pct}$ $\mathrm{NaCl}$ solution for various specimens are shown in Figures 5 and 6, respectively. The ultimate tensile strength (UTS), 0.2 pct offset yield strength (0.2 YS), and elongation (El) of the tested specimens obtained from Figures 5 and 6 are listed in Tables IV and V, respectively. The SCC susceptibility of these specimens was thus determined by the elongation loss (El loss) calculated according to the following equation: ${ }^{[16]}$

$$
\text { El loss }=\left[1-\left(\mathrm{El}_{\mathrm{SCC}} / \mathrm{El}_{\mathrm{SSRT}}\right)\right] \times 100 \mathrm{pct}
$$



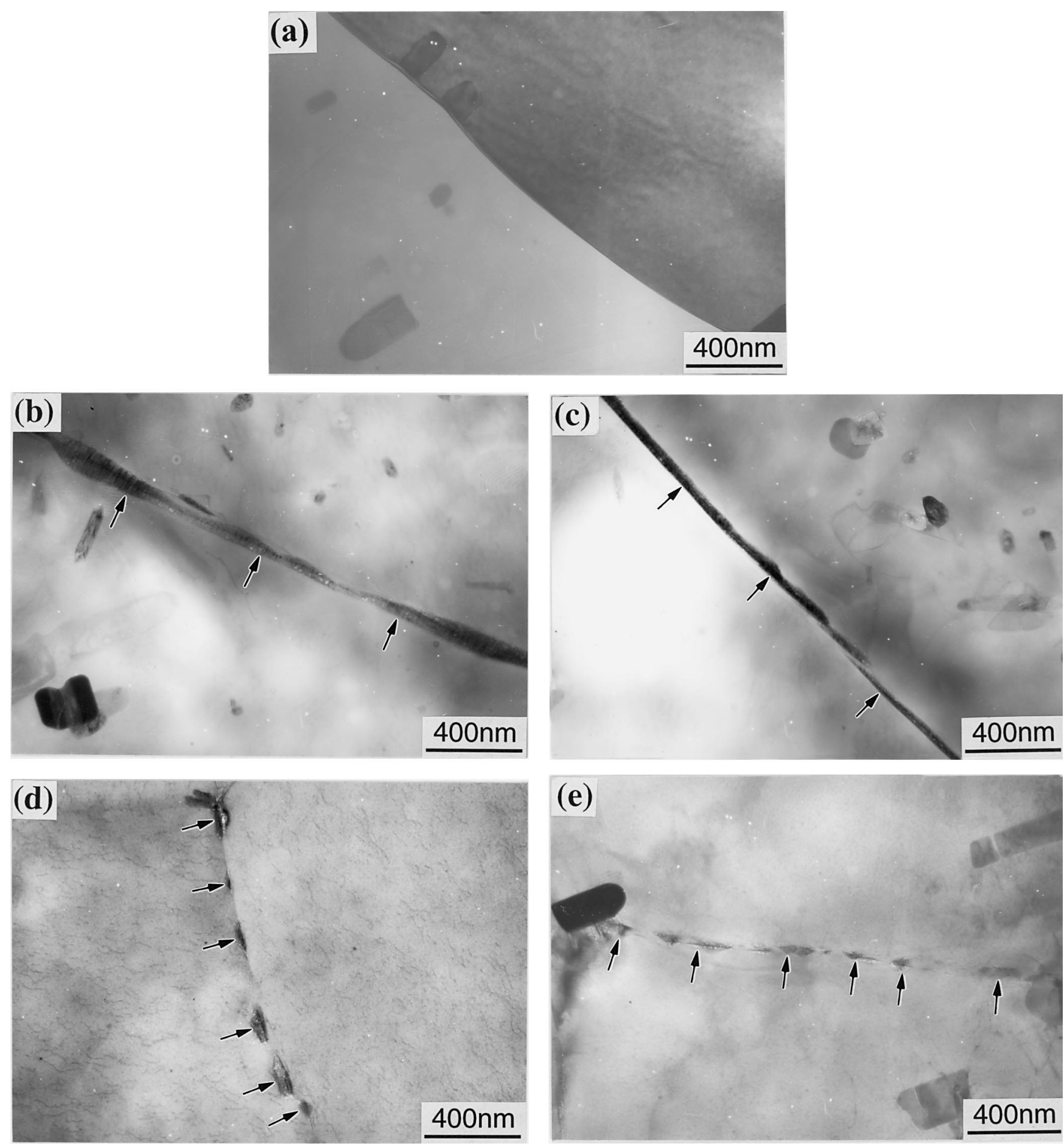

Fig. 4-STEM observations of the microstructure of various Al 5083SP specimens showing the grain boundary precipitates indicated by arrows: (a) S1, (b) $\mathrm{S} 2,(c) \mathrm{S} 3,(d) \mathrm{S} 4$, and (e) S5.

Table III. Tensile Properties $\left(\dot{\varepsilon}=10^{-3} / \mathrm{s}\right)$ of the Various Specimens Shown in Table II

\begin{tabular}{cccc}
\hline Specimen & UTS $(\mathrm{MPa})$ & 0.2 YS $(\mathrm{MPa})$ & El $(\mathrm{Pct})$ \\
\hline S1 & 339 & 162 & 19.2 \\
S2 & 294 & 147 & 11.1 \\
S3 & 326 & 159 & 24.6 \\
S4 & 295 & 147 & 13.2 \\
S5 & 324 & 157 & 23.8 \\
\hline
\end{tabular}

where $\mathrm{El}_{\mathrm{SSRT}}$ and $\mathrm{El}_{\mathrm{SCC}}$ are the elongation measured after SSRT in air and in 3.5 pct $\mathrm{NaCl}$ solution, respectively. From Table V, it can be seen that the elongation loss of the superplastically formed specimen (S2) and the specimen heat treated with the same thermal processes as the superplastic forming (S3) were 81.2 and 73.6 pct, respectively, as compared to that of the as-received specimen (S1). After postannealing treatment $\left(345^{\circ} \mathrm{C}, 1\right.$ hour $)$, the elongation loss of the specimens (S4 and S5) was reduced to 14.3 and 6.9 pct, respectively. 


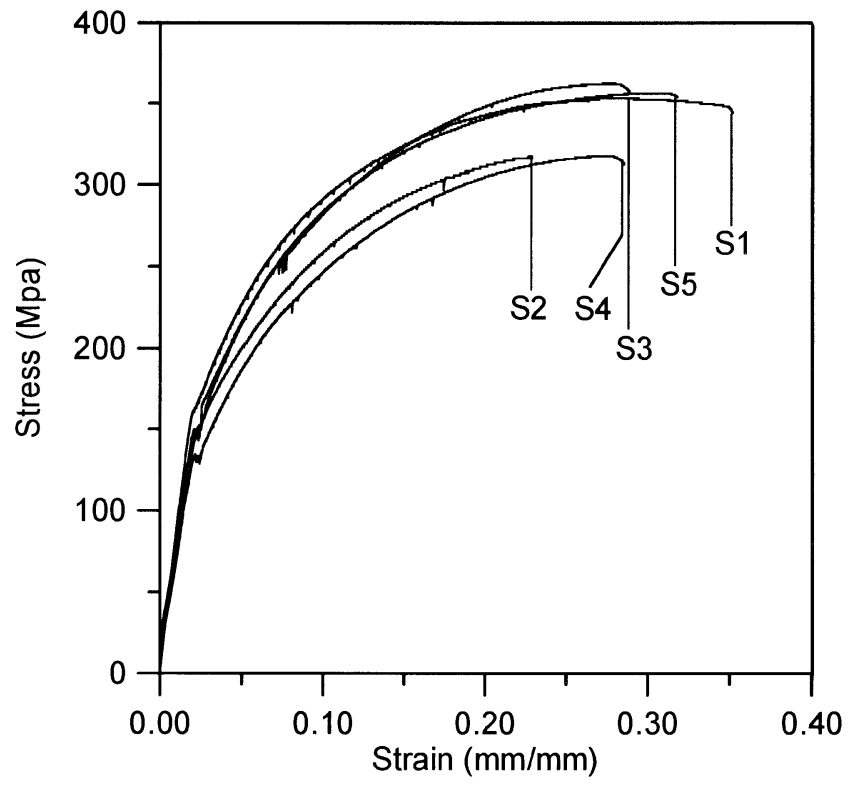

Fig. 5-Stress-strain curves of the slow strain rate tests in air for the various Al 5083SP specimens $\left(\varepsilon=4 \times 10^{-6} / \mathrm{s}\right)$.

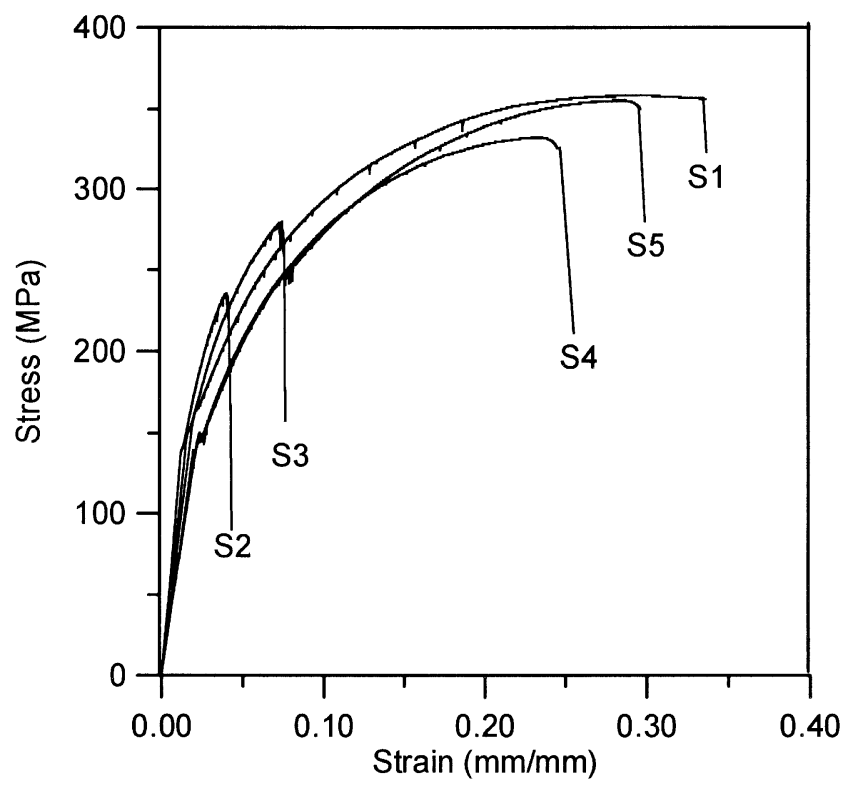

Fig. 6-Stress-strain curves of the slow strain rate tests in 3.5 pct $\mathrm{NaCl}$ solution for the various Al 5083SP specimens $\left(\varepsilon=4 \times 10^{-6} / \mathrm{s}\right)$.

. Table IV. Results of the Slow Strain Rate Tested in Air $\left(\varepsilon=4 \times 10^{-6} / \mathrm{s}\right)$ for the Various Specimens Shown in Table II

\begin{tabular}{cccc}
\hline Specimen & $\mathrm{UTS}_{\text {SSRT }}(\mathrm{MPa})$ & $0.2 \mathrm{YS}_{\mathrm{SSRT}}(\mathrm{MPa})$ & $\mathrm{El}_{\text {SSRT }}(\mathrm{Pct})$ \\
\hline S1 & 352 & 160 & 35.2 \\
S2 & 316 & 125 & 22.9 \\
S3 & 363 & 150 & 28.9 \\
S4 & 318 & 125 & 28.6 \\
S5 & 356 & 151 & 31.8 \\
\hline
\end{tabular}

The results implied that the coarsening of the intergranular precipitation layer into the discrete precipitation particles had effectively alleviated the sensitization effect of the $\beta$
Table V. Results of the Slow Strain Rate Tested in 3.5 Pct NaCl Solution $\left(\varepsilon=4 \times 10^{-6} / \mathrm{s}\right)$ and the Elongation Percentage Loss for the Various Specimens Shown in Table II

\begin{tabular}{cccrr}
\hline Specimen & $\begin{array}{c}\mathrm{UTS}_{\mathrm{SCC}} \\
(\mathrm{MPa})\end{array}$ & $\begin{array}{c}0.2 \mathrm{YS}_{\mathrm{SCC}} \\
(\mathrm{MPa})\end{array}$ & $\begin{array}{c}\mathrm{El}_{\mathrm{SCC}} \\
(\mathrm{Pct})\end{array}$ & $\begin{array}{c}\mathrm{El} \mathrm{Loss} \\
(\mathrm{Pct})\end{array}$ \\
\hline S1 & 358 & 164 & 33.6 & 4.5 \\
S2 & 251 & 136 & 4.3 & 81.2 \\
S3 & 360 & 142 & 7,6 & 73.6 \\
S4 & 331 & 132 & 24.5 & 14.3 \\
S5 & 355 & 151 & 29.6 & 6.9 \\
\hline
\end{tabular}

phase, as shown in Figures 4(d) and (e), respectively. Furthermore, the elongation losses of the superplastically formed specimens (S2 and S4), regardless of whether undergoing further annealing treatment, were only about $8 \mathrm{pct}$ larger than those of the specimens that were not superplastically formed (S3 and S5). In addition, the SCC susceptibility of the 1-mm-thick specimens, treated with the same thermal process as S3 and S5, respectively, also without superplastic forming, were similar to those of S3 and S5, respectively. It is thus clear that cavitation effects account for the difference of ductility loss between the superplastically formed specimens (S2 and S4) and the specimens without superplastic forming (S3 and S5).

Fractographs of various specimens tested at the strain rate of $10^{-3} / \mathrm{s}$ in air, presented in Figure 7, showed that all the specimens were dimple fractured, similar to the observation made by Patterson of the fracture of the annealed $5083 \mathrm{Al}$ alloy. ${ }^{[17]}$ Such a transgranular dimple fracture mode also appeared in all specimens after the slow strain rate test $(\varepsilon=$ $4 \times 10^{-6} / \mathrm{s}$ ) in air, indicating transgranular ductile fracture, as shown in Figure 8. However, the results were quite different for the specimens after the slow strain rate test in 3.5 pct $\mathrm{NaCl}$ solution. In these cases, it can be clearly seen that the S1, S4, and S5 specimens still showed a transgranular dimple fracture, as shown in Figures 9(a), (d), and (e), while the S2 and S3 specimens revealed severe intergranular fracture surfaces (Figures 9(b) and(c)).

\section{DISCUSSION}

The thickness of the superplastically formed workpiece is thinner at the corner, as shown in Figure 2(b). However, since the central part of the pan workpiece were attached first to the wall of the die during superplastic forming, the corner part continuously deformed after that. This phenomenon was similar to the superplastic forming of 7475 and 8090 aluminum alloys. ${ }^{[13]}$ The difference of the grain-growth rate between the specimens with and without superplastic forming was due to the deformation induced dynamic grain growth of the former, similar to that obtained in a tensile test of this alloy at $550{ }^{\circ} \mathrm{C}$, as reported by Verma et al. ${ }^{[10]}$ On the other hand, cavitations found in the superplastically formed specimens, especially at the triple grain boundaries, shown in Figure 3, were similar to those of the superplastically formed $\mathrm{Al} 7475$ workpieces in our previous study. ${ }^{[15]}$ Aluminum alloys are cavitation sensitive materials for superplastic forming ${ }^{[7-10,18]}$ Cavitation has also been reported for high-temperature deformation under cree $^{[19]}$ and fatigue ${ }^{[20]}$ conditions as well as during superplastic flow. 

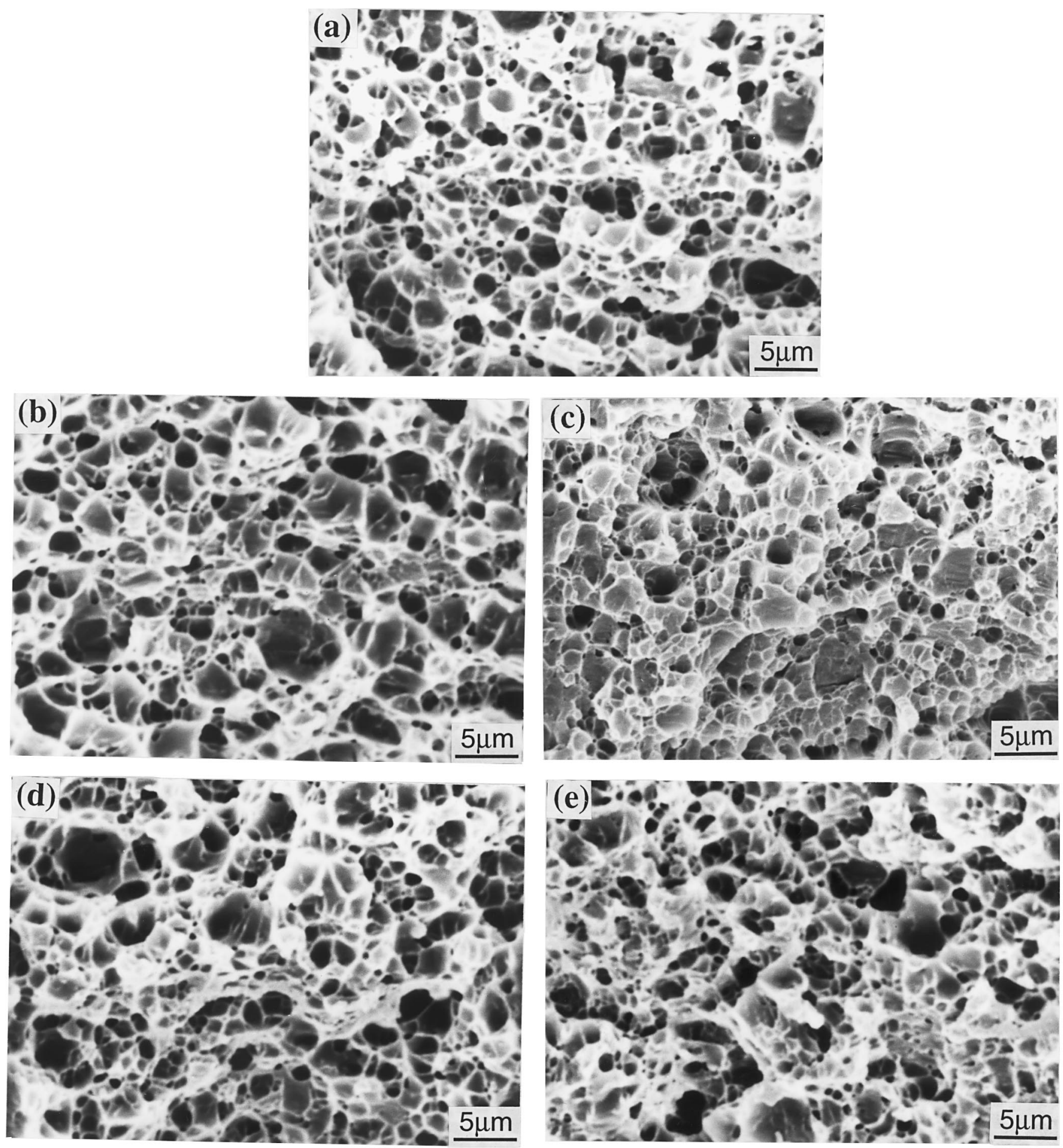

Fig. 7-Fractographs of the various Al 5083SP specimens after tensile tests at a strain rate of $10^{-3} / \mathrm{s}$ in air: (a) S1, (b) S2, (c) S3, (d) S4, and (e) S5.

As can be seen from Figure 4, the grain boundary precipitates changed clearly after postforming annealing. The discrete nature of the grain boundary precipitates was due to the coarsening of these $\mathrm{Mg}_{2} \mathrm{Al}_{3}$. It is reasonable to speculate that the discrete precipitation particles in S4 and S5 specimens were coarsened from the intergranular precipitation layer in S2 and S3 specimens during the postforming annealing treatment. Mazurkiewicz, ${ }^{[21]}$, Binger et al. ${ }^{[22]}$ and Hollingsworth and Hunsicker ${ }^{[23]}$ have reported that the corrosion potential of the $\beta$ phase and the $\mathrm{Al}$ matrix were $-1.15 \mathrm{~V}$ (vs SCE) and $-0.82 \mathrm{~V}$ (vs SCE), respectively. The more active corrosion potential of $\beta$ phase, in comparison with the Al matrix, will lead to the anodic dissolution of these precipitates at grain boundaries and accelerate the intergranular corrosion of the specimens. Such a sensitization effect should be more pronounced for specimens possessing a continuous precipitation layer than for those specimens containing discrete precipitation particles. 

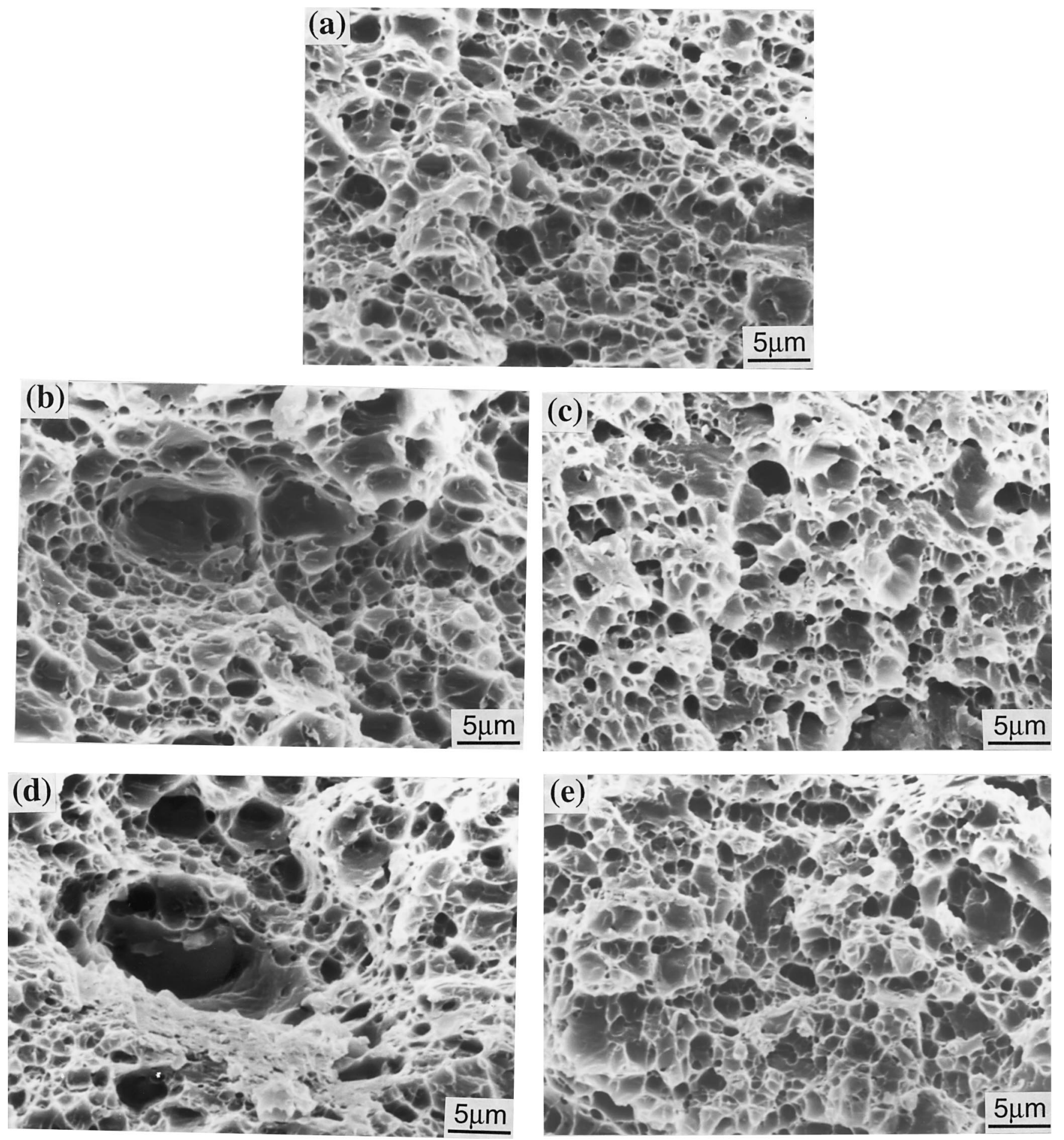

Fig. 8-Fractographs of the various Al 5083SP specimens after slow strain rate tests $\left(\varepsilon=4 \times 10^{-6} / \mathrm{s}\right)$ in air: (a) S1, (b) S2, (c) S3, (d) S4, and (e) S5.

From Figure 4, it was also found that a number of rectangular precipitation plates appeared in the grain interior in all specimens. The STEM-EDS analyses showed that these grain precipitates possessed a composition of the (Mn, $\mathrm{Fe}) \mathrm{Al}_{6}$ intermetallic compound. Since the corrosion potential of such a $(\mathrm{Mn}, \mathrm{Fe}) \mathrm{Al}_{6}$ phase is similar to that of the $\mathrm{Al}$ matrix, its effect on the corrosion resistance of this alloy is minor, as reported by Hollingsworth and Hunsicker. ${ }^{[23]}$ The existence of $(\mathrm{Mn}, \mathrm{Fe}) \mathrm{Al}_{6}$ precipitates in the grain interior should also be irrelevant to the SCC susceptibility of the Al 5083SP specimens in the present study.

From Table III, it is clear that the degradation of the ductility of the Al 5083SP alloy after superplastic forming was more serious than that of the tensile strength. It can also been seen that the tensile strength of the specimens S3 and S5 decreased only slightly, while their elongations increased as compared with the as-received material (S1) most likely because of the age softening and anneal softening 

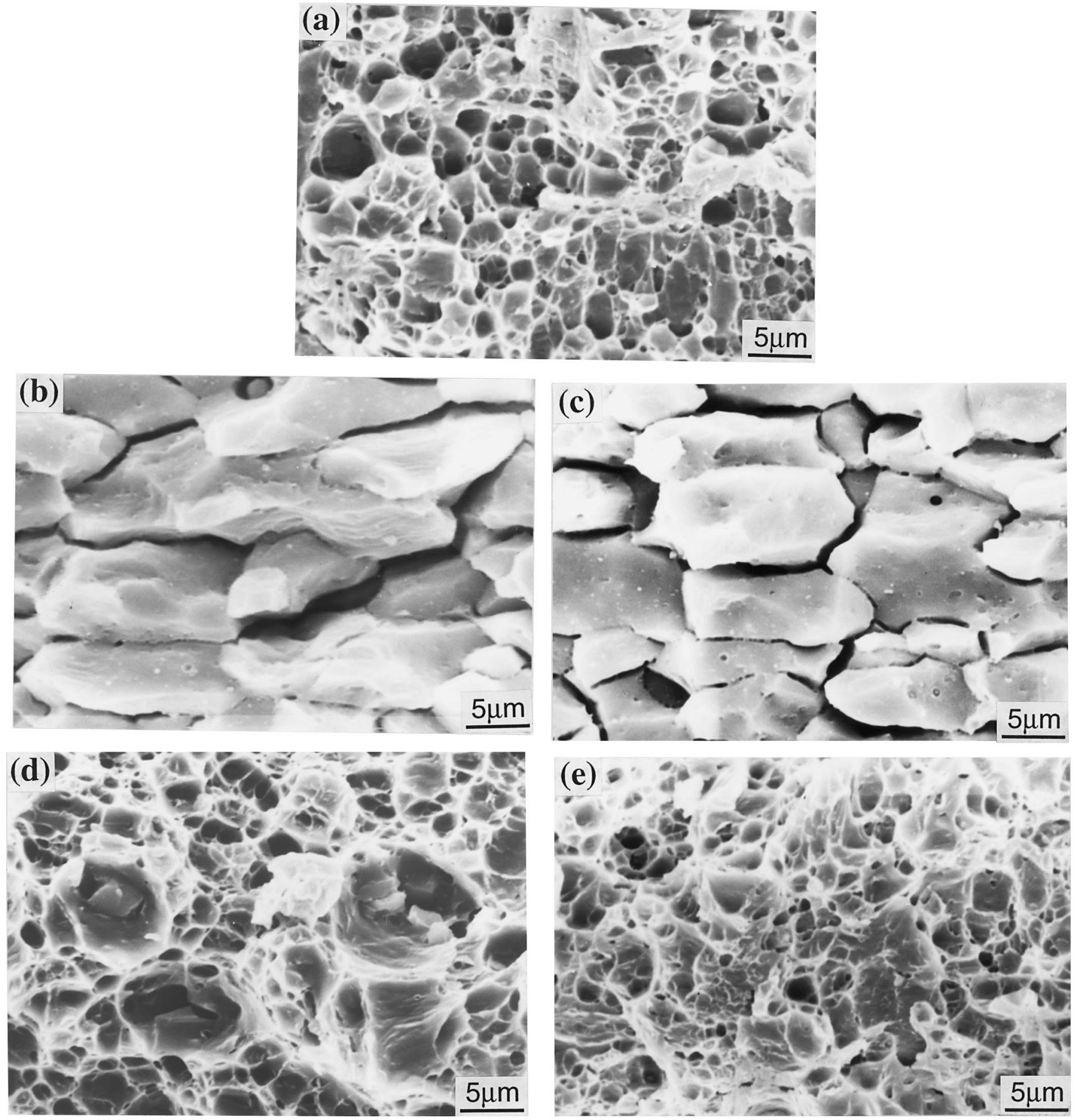

Fig. 9-Fractographs of the various Al 5083SP specimens after slow strain rate tests $\left(\varepsilon=4 \times 10^{-6} / \mathrm{s}\right)$ in 3.5 pct $\mathrm{NaCl}$ solution: (a) S1, (b) S2, (c) S3, (d) $\mathrm{S} 4$, and $(e) \mathrm{S} 5$.

of these specimens. ${ }^{[2]}$ From these results, it is obvious that the severe degradation of the tensile properties of both the superplastically formed and postannealed specimens (S2 and S4) can be attributed to the cavities formed during superplastic forming.

The thermal process of superplastic forming $\left(500{ }^{\circ} \mathrm{C}, 1\right.$ hour) led to very severe SCC for the Al 5083SP alloy in the $3.5 \mathrm{pct} \mathrm{NaCl}$ solution, as shown in Table V. Correlating to the observations of continuously distributed $\beta$ phase at the grain boundaries of S2 and S3 specimens (Figures 4(b) and (c)), the severe SCC of S2 and S3 should be attributed to the sensitization effect of these intergranular precipitation layers. On the other hand, the elongation loss of the postforming annealed specimens (S4 and S5) was reduced to 14.3 and $6.9 \mathrm{pct}$, respectively. The results implied that the postforming annealing led to the coarsening of the intergranular precipitation layer into the discrete precipitation particles, which effectively alleviated the sensitization effect of the $\beta$ phase. Furthermore, the elongation losses of the superplastically formed specimens (S2 and S4), regardless of 
whether undergoing further annealing, were only about 8 pct larger than those of the specimens that were not superplastically formed (S3 and S5). The results in this case corresponded to the cavitation effect accompanying the superplastic forming on the SCC susceptibility.

Comparing the influence of the sensitization effect to that of the cavitation effect, it can be seen that the ratio of the former to the latter was about 10:1, as quantitatively evaluated from the difference of the elongation percentage loss data shown in Table V. Furthermore, for considering the effect of the thickness of tensile specimens on the SCC behavior, two sets of 1-mm-thick specimens were also treated under the same thermal process as S3 and S5, respectively. Results of SSRT showed that the El losses were 74.2 and 7.1 pct, respectively, which were similiar to those of the 2-mm-thick specimens, as shown in Table V. Obviously, the effects of the thickness of tensile specimens on the SCC susceptibility were minor. Therefore, the sensitization effect was the primary factor for the severe SCC susceptibility of the superplastically formed Al 5083SP alloy, while the cavitation effect played only a minor role.

The distinction between the brittle fractographic features of S2 and S3 (Figures 9(b) and (c)) and the ductile fractographic features of all the other specimens (Figures 7, 8, and 9(a), (d), and (e)) can be attributed to the continuous precipitation of $\beta$ phase for the S2 and S3 specimens shown in Figures 4(b) and (c), respectively. As discussed above and reported in the literature, ${ }^{[21,22,23]}$ the more active corrosion potential of $\beta$ phase led to the anodic dissolution of these precipitates at grain boundaries and accelerated the intergranular corrosion of the specimens in the 3.5 pet $\mathrm{NaCl}$ solution. Therefore, brittle fracture surfaces were observed for the sensitization specimen. Furthermore, The fracture characteristics shown in Figure 9 were consistent with the tensile properties given in Table V. It is obvious that the ductile transgranular fracture of S1, S4 and S5 specimens also led to a higher elongation, as compared with the lower elongation of the intergranularly fractured S2 and S3 specimens.

\section{CONCLUSIONS}

The superplastically formed Al 5083SP specimen (S2) and the specimen $(\mathrm{S} 3)$ heat treated under the same thermal process as that of the superplastic forming $\left(500{ }^{\circ} \mathrm{C}\right.$ for 1 hour) suffered severe SCC susceptibility. This phenomenon was primarily attributed to the sensitization effect of the continuously distributed intergranular $\beta$ phase, which resulted in the highly anodic dissolution of the grain boundary. The cavitation effect accompanying the superplastic forming processes played only a minor role in SCC damage.
The susceptibility of SCC due to the sensitization of this alloy can be eliminated by a postforming annealing treatment at $345{ }^{\circ} \mathrm{C}$ for 1 hour (S4 and S5). The beneficial effect of postforming annealing was due to the coarsening of continuous intergranular precipitation layers into discrete particles at grain boundaries.

\section{REFERENCES}

1. R. Verma, A.K. Ghosh, S. Kim, and C. Kim: Mater. Sci. Eng., 1995, vol. 191A, pp. 143-50.

2. J. Wadsworth, T.G. Nieh, and O.B. Sherby: Superplasticity in Advanced Materials, Proc. JSRS Symp., S. Hori, M. Tokizane, and N. Furushiro, eds., Japan Society for Research on Superplasticity (JSRS), Tokyo, 1991, pp. 13-22.

3. R. Grimes and R.G. Butler: Superplasticity in Advanced Materials, Proc. JSRS Symp., S. Hori, M. Tokizane, and N. Furushiro, eds., Japan Society for Research on Superplasticity (JSRS), Tokyo, 1991, pp. 771-76.

4. M.G. Vassilaros: in Life Predication of Corrodible Structure, R.N. Parkins, ed., NACE, Houston TX, 1994, pp. 1656-67.

5. R.A. Corbett and B.J. Soldanha: Metals Handbook, 9th ed., vol. 13, Corrosion, ASM, Metals Park, OH, 1988, pp. 239-41.

6. R.B. Niederberger, J.L. Basil, and G.T. Bedford: Corrosion, 1966, vol. 22, pp. 68-73.

7. Y.H. Tseng: Master's Thesis, National Taiwan University, Taiwan, 1996.

8. R. Verma, P.A. Friedman, A.K. Ghosh, S. Kim, and C. Kim: J. Mater. Eng. Perform., 1995, vol. 4, pp. 543-50.

9. H. Iwasaki, T. Mori, T. Tagata, M. Matsuo, and K. Higashi: Mater. Sci. Forum, 1997, vols. 233-234, pp. 81-88.

10. R. Verma, P.A. Friedman, A.K. Ghosh, S. Kim, and C. Kim: Metall. Mater. Trans. A, 1996, vol. 27A, pp. 1889-98.

11. D.J. Lloyd: Metall. Trans. A, 1980, vol. 11A, pp. 1287-94.

12. H. Iwasaki, K. Higashi, S. Tanimura, T. Komatubara, and S. Hayami: Superplasticity in Advanced Materials, Proc. JSRS Symp., S. Hori, M. Tokizane, and N. Furushiro, eds., Japan Society for Research on Superplasticity (JSRS), Tokyo, 1991, pp. 447-52.

13. J.C. Chang: Ph.D. Thesis National Taiwan University, Taiwan, 1998.

14. B.J. Dunwoody, R.J. Stracey, and A.J. Barnes: Materials Research Society Symposia Proceedings M.J. Mayo, M. Kobayashi, and J. Wadsworth, eds., Materials Research Society, Pittsburgh, PA, 1990, vol. 196, pp. 161-66.

15. T.C. Tsai, J.C. Chang, and T.H. Chuang: Metall. Mater. Trans. A, 1997, vol. 28A, pp. 1997-2113.

16. D. Nguyen, A.W. Thompson, and I.M. Bernstein: Acta Metall., 1987, vol. 35 , pp. 2417-25.

17. R.A. Patterson: Corrosion, 1981, vol. 37, pp. 456-61.

18. Superplasticity in Aerspace-Aluminum, Proc. Int. Conf., R. Pearce and L. Kelly, eds., Ashford Press, Southampton, United Kingdom, 1985.

19. J.N. Greenwood, D.R. Miller, and J.W. Suiter: Acta Metall. 1954, vol. 2, pp. 250-58.

20. L.F. Coffin, Jr.: Proc. Int. Conf. on Fatigue-Chemistry, Mechanics and Microstructure, NACE, Houston, TX, 1972, pp. 590-600.

21. B. Mazurkiewicz: Corr. Sci., 1983, vol. 23, pp. 687-96.

22. W.W. Binger, E.H. Hollingsworth, and D.O. Sprowls: in Aluminum, K.R. Van Horn, ed., ASM, Metals Park, OH, 1967, p. 209.

23. E.H. Hollingsworth and H.Y. Hunsicker: Metals Handbook, 9th ed., vol. 13, Corrosion, ASM, Metals Park, OH, 1988, pp. 583-609.

24. J.E. Hatch: Aluminum Properties and Physical Metallurgy, ASM, Metals Park, OH, 1984, pp. 105-33. 